EESTI NSV TEADUSTE AKADEEMIA TOIMETISED. XVII KÖIDE

KEEMIA * GEOLOOGIA, 1968, Nr. 2

ИЗВЕСТИЯ АКАДЕМИИ НАУК ЭСТОНСКОЙ ССР. ТОМ ХVII

ХИМИЯ * ГЕОЛОГИЯ. 1968, № 2

А. ФОМИНА, Л. ПОБУЛЬ, З. ДЕГТЕРЕВА, Л. НАППА

\title{
К ВОПРОСУ ОБ ИЗУЧЕНИИ ХИМИЧЕСКОЙ ПРИРОДЫ КЕРОГЕНА ГОРЮЧИХ СЛАНЦЕВ
}

Кероген, вернее керогены горючих сланцев, согласно имеющимся сведениям, несомненно представляют особый класс каустобиолитов. Кероген кукерсита Приба.ттнйского бассейна, один из представителей этого класса, относится к древнейшнм образованиям твердого органического материала морского происхождения, отличается своеобразными свойствами, которые нельзя объяснить только тем, что он возник в то время, когда наземной растительности почти не существовало. Диктионемовый сланец Прибалтики и Швеции - более древний каустобнолит, однако его кероген имеет иную природу и по свойствам он ближе ко многим более поздним образованиям керогенового типа и даже к бурым углям.

Своеобразие керогена кукерсита привлекало к себе внимание ученых уже с начала $\mathrm{XX}$ столетия. Далеко не полный перечень опубликованных ими результатов исследований, в основном касающихся окислительной деструкции керогена, приводится в списке литературы $\left[{ }^{1-14}\right]$.

Окислительная деструкция углей щелочным перманганатом калия и идентификация растворимых продуктов реакции многое прояснила в изучении каустобиолигәв гумусовой природы. Естественно, что этот метод был привлечен и к изучению керогенов горючих сланцев, в том числе и кукерсита. Однако условия окисления, разработанные для углей, оказались недостаточно эффективными в применении к изучению керогена, хотя и позволили выяснить ряд весьма важных положений. Исследованиями П. Когермана, А. Л. Дауна и Г. В. Химуса, В. Ланина и М. Прониной и А. Кокурина в продуктах деструкции не было установлено бензокарбоновых кислот, при этом Ланин и соавторы практически окислили весь углерод до растворимых соединений. В продуктах деструкции, правда в незначительных количествах, были определены насыщенные жирные кислоты - уксусная, пропионовая и масляная, а из двухосновных - янтарная и адипиновая. * Однако в работах перечисленных авторов основное количество углерода, содержащегося в керогене кукерсита, было индентифицировано в виде щавелевой кислоты и двуокиси углерода, т. е. в виде соединений, не позволяющих однозначно определить продуцировавшие их структуры $\left[{ }^{15}\right]$. Они могли легко сбразоваться как из оксиароматических, так и из алифатических структурных элементов керогена. Было лишь ясно, что в керогене кукерсита нет структур, устойчивых к данному окислителю, отсутствуют и струкгуры, могущие в заметных количествах образовывать бензокарбоновые кислоты, но что в этом веществе в каких-то количествах (?) имеются структурные элементы, образующие при окислении жирные монои дикарбоновые кислоты.

* А. Д. Кокурин. Изучение природы органической массы сланца Ленинградской области. Кандидатская диссертация. Технологический институт им. Ленсовета. Л., 1938. 
П. Когерман при изучении керогена кукерсита придавал важное значение методам окислительной деструкции. Эта традиция в Институте химии АН ЭССР не только была сохранена, но и получила после его смерти широкое развитие.

Исследования по разработке условий окисления керогена щелочным перманганатом калия практически были начаты с 1952 г.; изучали влияние температуры и времени окисления на выход и состав продуктов деструкции (по групповому составу), определяли количество нерастворимого остатка и его элементарный состав [16]. Оказалось, что при более низкой температуре $\left(50^{\circ} \mathrm{C}\right)$ можно с меньшим количеством окислителя полностью деструктировать кероген до растворимых соединсний. Однако полное расщепление керогена при $50^{\circ}$ требовало слишком длительного времени $(354$ и) и за этот период подавляющая часть углерода превращалась в двуокись углерода и щавелевую кислоту.

Опыты $\left(100^{\circ}\right)$ по изучению влияния времени на выход продуктов окисления показали, что чем меньше контакт продуктов деструкции керогена с окислителем, тем ниже суммарный выход двуокиси углерода и щавелевой кислоты, и при этом выход более сложных органических кислот значительно увеличивается, а общая глубина деструкции керогена снижается. Оставалось выяснить правомерность отнесения результа́тов частичного окисления керогена к керогену в целом. Для этого были проведены опыты по расщеплению керогена до различной глубины. Нерастворимый остаток отделялся от растворимых продуктов и двуокиси марганца и после высушивания в вакууме до постоянного веса подвергался анализу, в том числе на содержание углерода и водорода. Результаты анализа приведены в табл. 1.

Таблица 1

Элементарный состав нерастворимых остатков керогена при различной глубине окисления

\begin{tabular}{l|c|c|c|c|c|c}
\hline \multirow{2}{*}{ Элементы } & \multirow{2}{*}{$\begin{array}{c}\text { Исходный } \\
\text { кероген, } \\
\%\end{array}$} & \multicolumn{3}{|c}{ Выход нерастворимых остатков керогена, \% } \\
\cline { 5 - 7 } & & 75 & 50 & 24 & 12 & 8 \\
\hline & 77,0 & 76,3 & 76,6 & 76,2 & 75,8 & 76,0 \\
Углерод & 9,6 & 9,5 & 9,5 & 9,8 & 9,8 & 9,7 \\
Водород & 13,4 & 14,2 & 13,9 & 14,0 & 14,4 & 14,3 \\
Гетероатомы & 8,0 & 8,0 & 8,0 & 7,8 & 7,7 & 7,8
\end{tabular}

Полученные результаты не только подтвердили правомерность распространения результатов частичного окисления на кероген в целом, но и показали существенное отличие этого процесса окисления от процесса окисления его кислородом воздуха [7,17]. Если в последнем случае при окислении происходит очевидная перестройка органического вещества с гумификацией его, то при окислении щелочным перманганатом калия происходит как бы послойное отщепление его, при котором незатронутая окислением часть керогена по составу остается практически нензмененной.

Результаты предыдущих опытов послужили основой для развития исследований по частичному окислительному расщеплению керогена щелочным перманганатом калия. Окисление проводилось при $50^{\circ}$. Часть. опытов велась с заданным расходом окислителя, при соотношении окислителя и керогена $4: 1\left[^{18}\right]$. В серии окислений при той же температуре переменной была продолжительность опыта (ступенчатое окисление, с 
длительностью одной ступени от 0,2 до 2,5 и и непрерывное - до 70 и). Окислитель во всех этих опытах подавался небольшими порциямі, чтобы не создавать большого избытка его. Таким образом около $78 \%$ окисленного углерода удалось получить в виде органических продуктов (табл. 2), при этом в щавелевую кислоту перешло 6,4\% углерода керогена, а суммарно с двуокисью углерода - 28,7\%. В опытах других исследователей $[6,11,12]$ основное количество окисленного углерода - 80 $-90 \%$ - расщеплялось до двуокиси углерода и щавелевой кислоты. Такой большой выход растворимых в щелочи органических продуктов окисления керогена кукерсита был получен впервые. Поэтому интересно было подробно исследовать эти вещества.

Таблица 2

Результагы ступенчатого и непрерывного окисления керогена кукерсита щелочным перманганатом калия при $50^{\circ}$

\begin{tabular}{|c|c|c|c|c|c|c|c|c|c|c|}
\hline \multirow{3}{*}{ 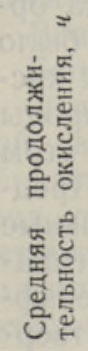 } & \multirow{3}{*}{ 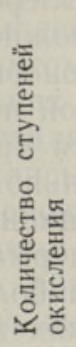 } & \multirow{3}{*}{ 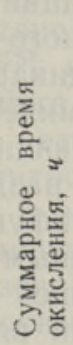 } & \multirow{3}{*}{ 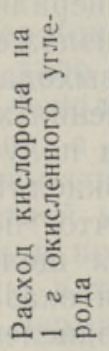 } & \multicolumn{5}{|c|}{$\begin{array}{l}\text { Содержание углерода окисленного ке- } \\
\text { рогена в органических соединениях, \% }\end{array}$} & \multirow{3}{*}{ 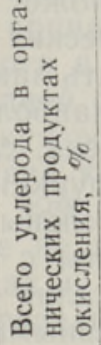 } & \multirow{3}{*}{ 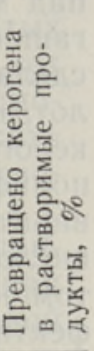 } \\
\hline & & & & \multirow{2}{*}{ 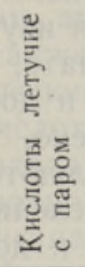 } & \multirow{2}{*}{ 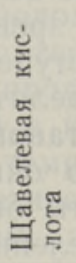 } & \multirow{2}{*}{ 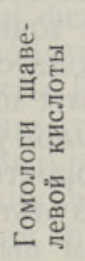 } & \multicolumn{2}{|c|}{$\begin{array}{l}\text { Нерастворимые } \\
\text { в воде }\end{array}$} & & \\
\hline & & & & & & & 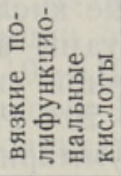 & 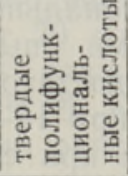 & & \\
\hline $\begin{array}{l}0,20 \\
0,57\end{array}$ & $\begin{array}{r}20 \\
101 \\
29 \\
1 \\
1 \\
1\end{array}$ & $\begin{array}{r}4, \\
57, \\
72,\end{array}$ & & 2, & $\begin{array}{r}6,4 \\
5,7 \\
4,2 \\
3,1 \\
6,1 \\
16,1\end{array}$ & $\begin{array}{r}8 \\
9 \\
12 \\
19\end{array}$ & $\begin{array}{r}8, \\
7, \\
9\end{array}$ & & & \\
\hline
\end{tabular}

Применение распределительной хроматографии на силикагеле позволило идентифицировать и количественно определить кислоты от уксусной до $H$-каприловой включительно $\left[{ }^{19}\right]$. С целью химической идентификации было предпринято препаративное хроматографическое выделение кислот, которые затем подвергались элементарному анализу. Из индивидуальных кислот были получены анилиды, определялись температура их плавления и элементарный состав. Судя по температурам плавления анилидов, кислоты от $\mathrm{C}_{4}$ до $\mathrm{C}_{8}$ включительно имели нормальное строение.

Применение распределительной хроматографии позволило идентнфицировать нелетучие с паром кислоты (не считая щавелевой кислоты, которая предварительно выделялась в виде оксалата аммония или 3 виде нерастворимой бариевой соли) и выделить их препаративно для химической идентификации. Было установлено семь кислот, от янтарной до себационовой включительно $\left(\mathrm{C}_{4}-\mathrm{C}_{10}\right)$ [ $\left.{ }^{20}\right]$, среди которых гомологи адипиновой кислоты $\mathrm{C}_{7}-\mathrm{C}_{10}$ составляли свыше $40 \%$. Последнее указывало на то, что кислоты $\mathrm{C}_{7}-\mathrm{C}_{10}$ обязаны своим происхождением не пяти- и шестичленным циклоалканам, а циклоалканам с бо́льшим числом атомов, возможно и с гетероциклическими структурными элементами макромолекулярного вещества керогена. Из данных табл. 2 видно, чіс углерода в виде гомологов щавелевой кислоты было получено мак- 
симально $24,0 \%$. Вместе с тем из этих данных следовало, что увеличение выхода кислот $\mathrm{C}_{4}-\mathrm{C}_{10}$ сопровождается уменьшением выхода нерастворимых в воде полифункциональных кислот [21,22].

Графическая интерпретация полученных результатов с привлеченпем данных других авторов $\left[{ }^{11,12}\right]$ позволила получить представление о механизме окислительного распада керогена: на полифункциональные осколки различного молекулярного веса $(305-1300)$ *, с частичным распадом его до моно- и дикарбоновых алифатических кислот, а также окислов углерода. В дальнейшем сложные полифункциональные кислоты расщепляются быстрее, чем образовавшиеся дикарбоновые кислоты. Это видно по снижению выхода нерастворимых в воде кислот и увеличению выхода моно- и дикарбоновых кислот, а также углерода в виде окислов. Нарастание выхода алифатических кислот происходит до тех пор, пока в реакционной среде имеются полифункциональные кнслоты. Далее распаду подвергаются сами алифатические кислоты, что сопровождается увеличением только окислов углерода. Такой распад может продолжаться лишь до полной минерализации углерода органических соединений. На основании вышеизложенного можно было сделать заключение, что для более высокого выхода дикарбоновых кислот, наиболее интересных с точки зрения изучения химической природы керогена, следует вести процесс ступенчато, а получающиеся при этом полифункциональные кислоты выделять и доокислять раздельно. Предварительными опытами было установлено, что полифункциональные кислоты с достаточной скоростью окисляются щелочным перманганатом калия при $18-20^{\circ}$. Результаты окисления оказались наиболее эффективными при суммарном выделении и доокислении вязкнх и твердых полифункциональных кислот (табл. 3).

Таблица 3

Выход продуктов окисления из керогена при ступенчатом раздельном доокмслении полифункциональных кислот

(при $18-20^{\circ} \mathrm{C}$ )

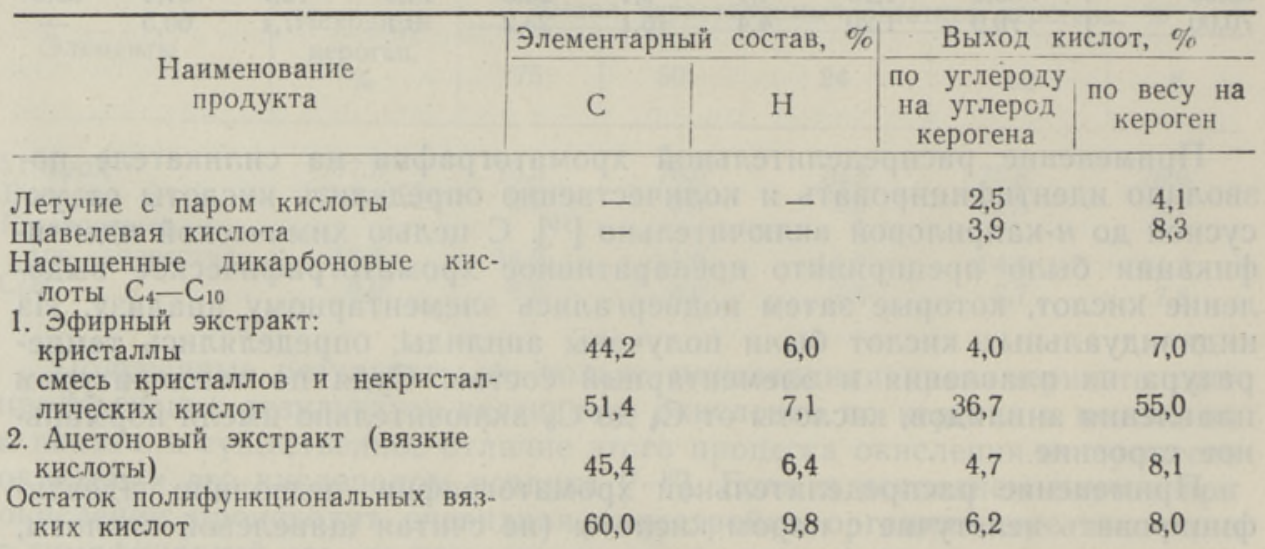

В этой серии опытов методом распределительной хроматографии было идентифицировано в виде кислот $\mathrm{C}_{4}-\mathrm{C}_{10} 38,4 \%$ углерода керогена. При доокислении $6,2 \%$ полифункциональных вязких кислот $69 \%$ углерода переходит в те же кислоты $\mathrm{C}_{4}-\mathrm{C}_{10}$. Следовательно, свыше $40 \%$ углерода керогена было получено в виде дикарбоновых кислот.

* Л. А. Побуль. Окисление керогена эстонского сланца-кукерсита марганцовокислым калием в щелочной среде. Автореферат кандидатской диссертации. Ин-т химин АН ӘССР. Таллин, 1957. 
Специальными опытами окисления сырых дикарбоновых кислот при 50 и $20^{\circ}$ установлено, что в использованных условиях температуры и врємени окисления 23-27\% углерода насыщенных кислот распадается до щавелевой кислоты и двуокиси углерода. Данные табл. 3 показывают, что $54 \%$ углерода получается в виде соединений насыщенного харәктера. Если учесть, что в процессе окисления около $25 \%$ образовавшихся кислот распадалось до двуокиси углерода и щавелевой кислогы, то количество исходного углерода керогена, способного продуцировать насыщенные кислоты, должно составлять около $70 \%$. Остальной углерод можно отнести как к алифатике, так и к оксиароматике. Последнее как бы отвечает и характеру соста̇ва смолы полукоксования кукерсита, содержащей свыше $20 \%$ фенолов.

Щелочной перманганат калия легко окисляет фенолы до щавелевой кислоты и двуокиси углерода, а азотная кислота позволяет выявить их, в большей или меньшей степени, в виде нитрофенолов. Это было показано в ряде работ по изучению химической прнроды гуминовых кислот, углей и др. [ $\left.{ }^{23-26}\right]$.

Взаимодействие керогена с азотной кислотой в условиях, принятых А. Беннингом [ $\left.{ }^{25}\right]$, не дало нитроароматических соединений, хотя в тех же условиях опыта с фенолом, анизолом и фенолформальдегидной смолой (в стадии резита), а также с термобитумом керогена кукерсита образовались нитроароматические продукты [27]. Взаимодействие керогена кукерсита с азотной кислотой в концентрации от 20 до $99 \%$ и с нитрующими смесями в пределах температур $10-110^{\circ}$ также не приводило к образованию нитроароматических веществ [28-30]. Как и при окислении щелочным перманганатом калия, продуктами окислительной деструкции керогена азотной кислотой являлись насыщенные моно- и, главным образом, дикарбоновые кислоты.

Следует отметить, что азотная кислота, особенно концентрирова:ная, взаимодействует с керогеном иначе, чем щелочной перманганат калия. 99\%-ная азотная кислота при температуре около $80^{\circ}$ вызывает грежде всего набухание керогена, превращение его в гелеобразную массу с последующим переходом ее в гомогенный раствор. Полное расщепление керогена до растворимых соединений в концентрированной азотной кислоте и органических растворителях при $80^{\circ}$ происходило за 1,5 , тогда как в случае окисления щелочным перманганатом калия приблизительно при этой же температуре требуется значительно больше времени (табл. 4).

Таблица 4

Сравнительные данные по окислению керогена кукерсита азотной кислотой и щелочным перманганатом калия

\begin{tabular}{|c|c|c|c|c|c|c|}
\hline \multirow[b]{2}{*}{ Окислитель } & \multirow{2}{*}{ 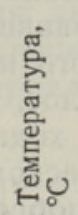 } & \multirow{2}{*}{ 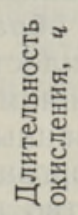 } & \multirow{2}{*}{ 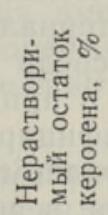 } & \multicolumn{3}{|c|}{$\begin{array}{c}\text { Выход органических } \\
\text { продуктов окисления, \% }\end{array}$} \\
\hline & & & & всего & $\begin{array}{c}\text { щавеле- } \\
\text { вой кис- } \\
\text { лоты }\end{array}$ & $\begin{array}{c}\text { гомологов } \\
\text { щавеле- } \\
\text { вой кис- } \\
\text { лоты }\end{array}$ \\
\hline $\begin{array}{l}\text { Щелочной перманганат } \\
\text { калия }\end{array}$ & 75 & 166 & 0,99 & 27,7 & 23,3 & 3 \\
\hline $99 \%$-ная азотная кислота & 80 & 1,5 & Нет & 104,9 & Следы & 47,6 \\
\hline
\end{tabular}

Выход углерода в органических продуктах при этом составил $77,5 \%$. Такой же выход достигается в результате окисления щелочным перманганатом калия при 33,5\%-ном превращении керогена (см. табл. 2). Из 
растворимых в крепкой азотной кислоте продуктов сложные полифункциональныє кислоты со средним молекулярным весом 1100 имели эмпирическую формулу следующего вида:

$$
\mathrm{C}_{45} \mathrm{H}_{66} \mathrm{~N}_{2}(\mathrm{COO})_{3,4} \cdot(\mathrm{COOH})_{4,3} \cdot(\mathrm{OH})_{3,9} \cdot \mathrm{NO}_{2} \text {. }
$$

Атомарное отношение водорода к углероду (приведено к углеводороду) этнх кислот составляет величину около 2. Смесь кислот, извлеченная :13 слабокислого раствора этиловым эфиром, нмела состав, приведенный в табл. 5.

Таблица 5

Компонентный состав насыщенных дикарбоновых кислот, полученных окислением керогена $99 \%$-ной азотной кислотой при $80^{\circ} \mathrm{C}$

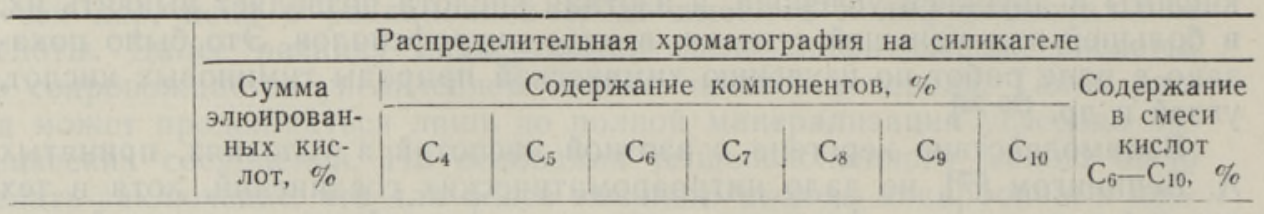

$Э$ Фирный

экстракт

94,0

19,0

$17,7 \quad 18,7 \quad 20,0$

7,9

$5,1 \quad 11,6$

63,3

В результате исследования взаимодействия керогена с азотной кислотой и тщательного изучения всех органических продуктов его деструкции установить ароматические соединения не удалось. Из этого можно было заключить, что оксиароматические структурные элементы в составе керогена кукерсита, видимо, не присутствуют в значительных количествах. Следовательно, около $30 \%$ углерода керогена оставалось «белым пятном» и после этого цикла исследований. В то же время высокий выход фенолов в смоле полукоксования кукерсита требовал своего объяснения.

Для перехода к следующему этапу, к более углубленному исследованию природы керогена, необходимо было снова изучить все имеющиеся в литературе данные исследований сланца-кукерсита, и не только химических, но и геологических, палеонтологических, микробиологических и др. Этот труд оказался весьма полезным, так как позволил выяснить условия образования материнского вещества керогена кукерсита. Результаты химических исследований, взятые отдельно, не позволяли правильно трактовать некоторые свойства керогена кукерсита и характер тех или иных его превращений. Так, например, геологические и палеонтологические данные явно говорили о том, что отложение органического материала, образовавшего кукерсит, происходиля не в восстановительной среде гнилостного ила, а в условиях достаточной аэрации воды даже в придонном слое, как об этом можно судигь по многочисленным литифицированным ходам червей в слоях сланцев и в обводненном коллоидном органическом материале. А. Эпик [ $\left.{ }^{31}\right]$ полагал, что органическое вещество приобрело устойчивую форму еще до полного использования кислорода, так как в противном случае не могла бы существовать донная фауна. Поэтому Эпик считает неприемлемым для кукерсита название «морской сапропелит».

Микробиологические исследования разложения органического материала в морской воде с достаточной аэрацией и опыты in vitro [32, 33] показали, что в этом случае углеводы фитопланктона и целлюлоза перерабатываются аэробными или факультативно аэробными бактериями, 
которые используют их не только в качестве энергетического источника, но и для ресинтеза слизи. При разложении целлюлозы и глюкозы миксобактериями было установлено, что от 20 до 27\% углерода исходных веществ остается в продуктах их жизнедеятельности $\left[{ }^{34}\right]$. С. Виноградский [35] указывает, что слизь миксобактерий не затрагивается никакнми микробами: «... Ни плесени, ни бактерин не могут, очевидно, развиваться за счет этой слизи».

Следовательно условия накопления материнского вещества керогена кукерсита указывают на возможность участия в общей структуре керотена структур углеводной природы. Известно, что углеводы легко окисляются щелочным перманганатом калия до щавелевой кислоты и двуокиси углерода. Әто вполне согласовалось с результатами окисления, но) не объясняло поведения кукерсита при полукоксовании - образование смолы с высоким содержанием фенолов.

Работами ряда специалистов по изучению углеводов было установлено, что углеводы как под влиянием термического воздействия, так и в природных условиях склонны превращаться в оксиароматические соединения, и не только в оксибензол, но и в полифенолы [36-39]. Эги данные позволили объяснить высокий выход фенолов при полукоксовании кукерсита. Однако до настоящего времени в литературе почти не имелось данных о наличии углеводных структур в керогене, кроме указаний на положительную микрохимическую реакцию вещества с рутениум рот на пектиновые вещества $\left[{ }^{40}\right]$, но и эту реакцию некоторые авторы не считают специфичной. Тем не менее на основании обобщения всех имевшихся по керогену данных и известных фактов из смежных областей науки было высказано предположение, что кероген кукерсита представляет собой макромолекулярное вещество - продукт диагенетического превращения вещества типа полиэфиров, в котором роль спиртовой части выполняла углеводная составляющая типа слизей миксобактерий и второй компонентой являлись в основном непредельные жирные кислоты, а также окси- и кетокислоты [41].

О протекании сложных реакций в процессе диагенеза органического материала свидетельствуют результаты исследований Н. Дилакторского [42], установившего, во-первых, что структурированная часть керогена представляет собой коллоидные глобулы, а не альги, как считал M. Залесский, и, во-вторых, что принятые за ядра альг образования микроглобул являются пузырьками газов, состоящих из смеси $\mathrm{CO}_{2}, \mathrm{H}_{2}$ и $\mathrm{CH}_{4}$. Несомненно, в веществе трехмерной структуры исчезла часть первоначальных связей и возникли новые связи. Поэтому естественно, что средний элементарный состав керогена уже не соответствует составу исходного органического вещества. Тем не менее можно было предположить, что ранняя литификация вмещающих карбонатных пород и отсутствие последующего метаморфизма обеспечили консервирование органического материала и сохранение в нем в значительной мере углеводных структур.

С целью установления углеводных структур в керогене методом прямого выделения была проведена серия исследований по гидролизу керогена 5\%-ной соляной кислотой (ступенчатым способом), как при атмосферном давлении, так и при $130^{\circ}$ в автоклаве $\left[{ }^{43-45}\right]$. Из гидролизатов были выделены и идентифицированы ксилоза, глюкоза, арабиноза, галактоза и следы рамнозы. Количественные соотношения удалось установить только для первых четырех, рамноза оказалась в очень незначительных количествах - ниже разрешающей способности фотометрнческого метода. 
Качественный анализ показал, что несмотря на низкое содержание в керогене азота, аминокислоты были найдены в гидролизатах. Как для проверки сингенетичности керогену идентифицированных сахаров, так и для проведения специального гидролиза с целью получения азотсодержащей части гидролизата была отобрана (в стерильных условиях) специальная проба сланца, которая для обогащения в лабораторных условиях обрабатывалась $5 \%$-ной соляной кислотой с целью удаления карбоната кальция. Контрольные серии гидролиза дали гидролизат, в котором были идентифицированы ранее указанные гексозы и пентозы. Гидролиз 6 н. соляной кислотой на кипящей водяной бане в течение 24 ч позволил получить азотсодержащую часть, которая была проанализирована на автоматическом анализаторе японской фирмы Хитачи. В результате было определено 20 аминокислот всех рядов, в том числе серосодержащие, гетероциклические и ароматические; однако основная часть их имела алифатическую природу.

Хотя содержание азота в керогене колеблется в пределах $0,2-0,7 \%$, а в исследованной пробе составляло $0,3 \%$, и, следовательно, общее содержание азотсодержащих структурных элементов в керогене кукерсита не превышает $5 \%$ от общей массы, тем не менее полученные результаты представляют интерес. Они указывают, насколько разнообразны по природе и строению структурные элементы керогена. Азотсодержащие структурные элементы, несомненно, не определяют основных свойств и структуры керогена. Кероген в основной своей части - жирового происхождения, но в его структуре немалую роль играют и вещества углеродной природы. К настоящему времени имеется подтверждение того, что в природе существуют вещества типа липоуглеводов $[46,47]$.

Чтобы завершить изучение основной структуры керогена кукерсита, очевидно необходимо уже перейти от анализа к синтезу - к получению веществ, моделирующих его основную структуру. Этот качественно новый этап изучения структуры керогена кукерсита находится в настоящее время в начальной стадии - в стадии развития синтетических работ. Завершение этих исследований позволит сделать окончательные выводы не только о природе, но и о строении этого весьма своеобразного каустобиолита.

\section{ЛИТЕРА Т Р А}

1. Фокин Л. Ф., Горный журнал, 2, 117-142 (1913).

2. З а лесский М. Д., Изв. АН. Сер. VI, т. II, ч. I, № 1-11, 3 (1917).

3. Lindenbein H. A. R., Arh. Sci. phys. natur., 3, 379, Genève (1921).

4. B rown Cr., The Oil-Shale of the Lothians, Edinburgh, 1912.

5. Kogerman P. N., Oil-Shale Research Laboratory University of Tartu, Estonia, Bull., No. 3 (1931).

6. Kogerman P. N., The Constitution of the Estonian Oil-Shale "Kukersite". Oil-Shale and Cannel Coal Proceedings of a Conference Held in Scotland, 1938.

7. Орлов Н. А. и Радченко О. А., Ж. прикл. хим., 7, № 8, 1476 (1934).

8. Ohtla E., Uurimusi lämmastikhappe toimest orgaanilisele ainele, Tartu, 1931.

9. Holmberg B., Transactions of Fuel Conference, 1, 680, London (1928).

10. Когерман П., Лутс К., Х юссе И., Химия эстонских сланцев, М.-Л., 1934.

11. Down A. L. and Himus G. W., J. Inst. Petrol. Technol., 27, 426 (1941).

12. Л анин В. А. и Пронина М. В., Изв. АН СССР, ОТН, № 10-11 (1944).

13. Когерм н П. К., Химия и генезис твердых горючих ископаемых. Тр. Первого Всесоюзного совещания, М., Изд-во АН СССР, 1953. 
14. Когерм ан П. К., Изв. АН ЭССР, 1, № 1, 108 (1952).

15. Randall R. B., Benger D. M., Groocock C. M., Proc. Roy. Soc., ser. A, 165, No. 922, 432 (1938).

16. Фомин а А. С., Побуль Л. Я., Изв. АН ЭССР, 2, № 1, 91 (1953).

17. Luts K., Der estländische Brennschiefer Kukersit, seine Chemie, Technologie und Analyse, Reval, 1934

18. Фомина А. С., Побуль Л. Я., Изв. АН ЭССР, 4, № 4, 587 (1955).

19. Фомина А. С., Побуль Л. Я., Изв. АН ЭССР, 2, № 4, 551 (1953).

20. Фомина А. С., Поб уль Л. Я., Изв. АН ЭССР, 4, № 1, 48 (1955).

21. Фомина А. С., Побуль Л. Я., Изв. АН ЭССР, 4, № 4, 587 (1955).

22. Побуль Л. Я., Фомина А. С., Изв. АН ЭССР, 6, № 2, 190 (1957).

23. Van Duuren B., W a rren F., J. S. African Chem. Inst., 3, 67 (1950).

24. Fuch s W., Stengel W., Brennstoff-Chem., 10, 303 (1929).

25. B e nn ing A., Brennstoff-Chem., 36, Nr. 3/4, 38 (1955).

26. Чуксанова А. А., Сергевв Л. Л. и Шорыгина Н. Н., Изв. АН CCCP, OXH, № 2, 250 (1956) .

27. Фомина А. С., Дегтерев а Э. А., Изв. АН ЭССР, 5, № 4, 276 (1956).

28. Фомина А. С. и Дегтерев а 3. А., В сб.: Горючие сланцы. Химия и технология, вып. 2, Ин-т химии АН ЭССР, Таллин, 1956, с. 7.

29. Д егтерев а 3. А., Фомин а А. С., В сб.: Горючие сланцы. Химия и технология, вып. 3, Ин-т химии АН ЭССР, Таллин, 1959.

30. Фомина А. С., Ильин А. И., В ески Р. Э., В сб.: Горючие сланцы. Химия и технология, вып. 4, Ин-т химии АН ЭССР, Таллин, 1961, с. 5.

31. Winkler N., Der Estländische Brennschiefer. Untersuchung, Gewinnung und Verwertung, Herausgeber H. Winkler, Mitarbeit von A. Opik, J. Reinwaldt usw., Reval, 1930.

32. B a ve n d a mm W., Arch. für Mikrob., 3, 205 (1932).

33. Имшенецкий А. А., Микробнология целлюлозы, М., Изд-во АН СССР, 1953.

34. Кононова М. М. и Александрова И. В., Микробиология, 18 , № 1,42 (1949).

35. В и н ог р ад ски ий С. Н., Микробиология почвы, М., Изд-во АН СССР, 1952.

36. Pictet A. et S a r a sin J., Helv. chim. acta, 39, 242 (1918).

37. Pictet A. und Vogel H., Fortschr. chem. Phys. u. physikal. Chem., S. A., 20, Nr. 4, 1 (1929).

38. Шорыгина Н. Н. и Перфилова Г. В., Докл. АН СССР, 114, № 5, 1040 (1957).

39. К у р с н о в А. Л., Синтез и превращение дубильных веществ в чайном растении, М., Изд-во АН СССР, 1952.

40. В ин оградов А. П., Бой ченко Е. А., Докл. АН СССР, 39, № 9, 398 (1943).

41. Фомин а А. С., Генезис твердых горючих ископаемых, М., Изд-во АН СССР, 1959 , c. 77.

42. Ди л акторский Н. Л., Изв. АН ЭССР, 9, № 2, 130 (1960).

43. Н а пп а Л., Фомина А., Иззв. АН ЭССР, 14, № 6, 163 (1965).

44. Фомм ин а А. С, Н а пп а Л., Изв. АН ЭССР. Химия *. Геология, 16, № 1,5 (1967)

45. Фомина а А. С., Н апп а Л. А., Химия твердого топлива, № 1, 8 (1967).

46. Ал имова Е. К., Аств ацатурьян А. Т., Болгова Т. Д. В сб.: Углеводы и углеводный обмен, М., 1962, с. 294.

47. Алимов а Е. К. В сб.: Углеводы и углеводный обмен в животном и растительном организмах, М., 1959 , с. 255.

Институт химии

Академии наук Эстонской ССР
Поступила в редакцию $5 /$ II 1968 
A. FOMINA, L. POBUL, Z. DEGTERJOVA, L. NAPPA

\section{PÓLEVKIVIKEROGEENI KEEMILISE LOOMUSE UURIMISEST}

Artiklis antakse ülevaade kukersiidi orgaanilise osa (kerogeeni) uurimisest ENSV TA Keemia Instituudis.

Esitatakse tulemused, mis saadi kerogeeni destruktiivsel oksüdeerimisel lämmastikhappega ja leeliskaaliumpermanganaadiga ning hüdrolüüsil soolhappega.

Eraldati ja identifitseeriti kerogeeni struktuurielemendid: rasvhapped $C_{2}-C_{8}$, küllastumata dikarboonhapped $\mathrm{C}_{2}$ ja $\mathrm{C}_{4}-\mathrm{C}_{10}, 2$ heksoosi, 2 pentoosi ja 20 aminohapet.

Esitatakse hüpoteese kerogeeni keemilise koostise ja tekkimise kohta.

\section{A. FOMINA, L. POBUL, Z. DEGTERYOVA, L. NAPPA}

\section{INVESTIGATIONS OF THE ORGANIC MATTER OF OIL SHALE (KUKERSITE)}

This report describes the investigations of the organic matter (kerogen) of oil shale (kukersite) carried out at the Institute of Chemistry of the Academy of Sciences of the Estonian SSR.

The results obtained by a destructive oxidation of kerogen with nitric acid and basic potassium permanganate and by hydrolysis with hydrochloric acid are discussed.

Fat acids $\mathrm{C}_{2}-\mathrm{C}_{8}$, nonsaturated dicarboxylic acids $\mathrm{C}_{2}$ and $\mathrm{C}_{4}-\mathrm{C}_{10}, 2$ hexoses, 2 pentoses and 20 aminoacids are evolved and identified as structural units of kerogen.

The opinion on the chemical structure and formation of kerogen of oil shale is presented. 